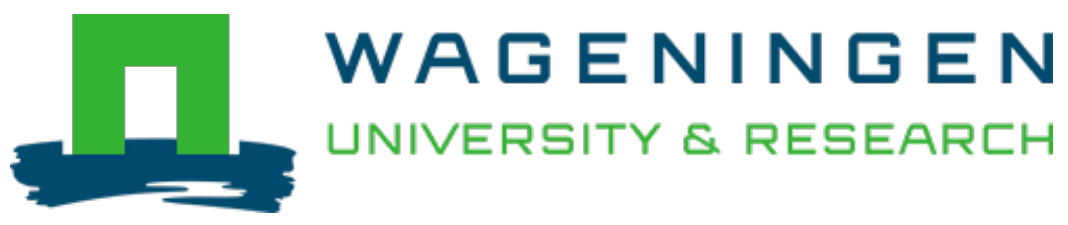

\title{
The mediating role of digital informal learning in the relationship between students' digital competency and their academic performance
}

Computers and Education

Mehrvarz, Mahboobe; Heidari, Elham; Farrokhnia, Mohammadreza; Noroozi, Omid

https://doi.org/10.1016/j.compedu.2021.104184

This article is made publicly available in the institutional repository of Wageningen University and Research, under the terms of article $25 \mathrm{fa}$ of the Dutch Copyright Act, also known as the Amendment Taverne. This has been done with explicit consent by the author.

Article 25 fa states that the author of a short scientific work funded either wholly or partially by Dutch public funds is entitled to make that work publicly available for no consideration following a reasonable period of time after the work was first published, provided that clear reference is made to the source of the first publication of the work.

This publication is distributed under The Association of Universities in the Netherlands (VSNU) 'Article $25 \mathrm{fa}$ implementation' project. In this project research outputs of researchers employed by Dutch Universities that comply with the legal requirements of Article $25 \mathrm{fa}$ of the Dutch Copyright Act are distributed online and free of cost or other barriers in institutional repositories. Research outputs are distributed six months after their first online publication in the original published version and with proper attribution to the source of the original publication.

You are permitted to download and use the publication for personal purposes. All rights remain with the author(s) and / or copyright owner(s) of this work. Any use of the publication or parts of it other than authorised under article $25 \mathrm{fa}$ of the Dutch Copyright act is prohibited. Wageningen University \& Research and the author(s) of this publication shall not be held responsible or liable for any damages resulting from your (re)use of this publication.

For questions regarding the public availability of this article please contact openscience.library@,wur.nl 


\title{
The mediating role of digital informal learning in the relationship between students' digital competence and their academic performance
}

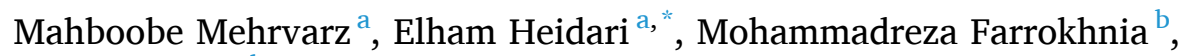 \\ Omid Noroozi ${ }^{\mathrm{b}}$ \\ ${ }^{a}$ Department of Educational Administration and Planning, Shiraz University, Shiraz, Iran \\ ${ }^{\mathrm{b}}$ Wageningen University and Research, Wageningen, the Netherlands
}

\section{A R T I C L E I N F O}

\section{Keywords:}

Academic performance

Digital competence

Digital informal learning

Higher education

Learning

\begin{abstract}
A B S T R A C T
Students' digital competencies are important for their academic performance. Although scholars have highlighted the importance of students' digital informal learning in developing their digital competence, the mediating role of digital informal learning between digital competence and academic performance have remained unexplored. Thus, this study aimed to investigate the mediating role of digital informal learning between higher education students' digital competence and their academic performance. The data were collected from 319 students from Shiraz University in Iran. Data were analysed using structural equation modeling via AMOS. The result showed a positive effect of the students' digital competence on their digital informal learning and academic performance. Moreover, digital informal learning as the mediator variable had a positive effect on the relationship between digital competence and students' academic performance. In conclusion, to improve students' academic performance, educators and curriculum designers should consider both their digital competence and their digital informal learning.
\end{abstract}

\section{Introduction}

The rapid development of digital technologies has spurred strong interest among scholars to employ these technologies for educational purposes, not only to facilitate learning in formal settings (Farrokhnia et al., 2019; Hassanzadeh et al., 2016; Heidari et al., 2020; Noroozi et al, 2016, 2018; Seo et al., 2021; Winkler et al., 2021) but also in informal, out of the class, settings (Chan et al., 2015; Coll \& Treagust, 2015; Hubbard, 2019; Song \& Lee, 2014). With the recent advent and affordance of new technologies, increasing attention has been paid to digital informal learning (DIL) and the way students learn in such settings (Reinders \& Benson, 2017). In DIL, there are no time and space restrictions (Yang, 2020). Thus, DIL provides learners with new opportunities to learn anywhere at any time (Ang et al., 2018, pp. 87-101; Jin et al., 2019; Jurkovič, 2019). DIL is driven primarily by learners' high interests and excitement because they are more motivated to learn in this technology-based learning environment (Sackey et al., 2015) and thus can better improve their academic performance (Doleck et al., 2019; Mishra, 2020).

Academic performance, as one of the most important indicators of success in universities (Mthimunye \& Daniels, 2020), refers to

\footnotetext{
* Corresponding author.

E-mail addresses: mehrvarzmahboobe66@yahoo.com (M. Mehrvarz), eheidari@shirazu.ac.ir (E. Heidari), mohammadreza.farrokhnia@wur.nl (M. Farrokhnia), omid.noroozi@wur.nl (O. Noroozi).
} 
students' ability to perform classroom tasks, problem-solving activities, and academic affairs (Hung, 2005; Yu et al., 2010). Although scholars reported that academic performance could be positively influenced by students' DIL experiences (Ali \& Naylor, 2010), the empirical research on DIL is still insufficient (He \& Li, 2019), especially regarding its effect on higher education students' academic performance (Baker, 2014). The picture is also unclear when it comes to influential factors that may regulate the DIL process and outcome (Chan et al., 2015). For instance, scholars claimed that DIL demands proper digital competence (Hubbard, 2019; Nyikes, 2018) to form students' optimal learning and behavior in such a digital-based learning environment (He et al., 2018). Digital competence, as one of the key competencies for lifelong learning (see Ferrari, 2013), is supported by digital literacy (Martin \& Grudziecki, 2006). Digital literacy is often referred to as media literacy focusing more on its functional dimension. Digital functional literacy or technical skills means having the practical skills needed to use digital technologies, including operational and creative skills (Falloon, 2020; Helsper et al., 2015). Although digital literacy is often used as a synonym for digital competence (Calvani et al., 2012; He \& Zhu, 2017; Ilomäki et al., 2011), they have distinct roots and meanings (Iordache et al., 2017). Digital literacy refers more to a set of skills and activities to achieve digital competence in ICT (Ferrari et al., 2014). According to scholars, the scope of digital competence is beyond digital literacy (Fraillon et al., 2014; Jin et al., 2020) and includes attitude and mindset besides the skills (Janssen et al., 2013). Recent studies suggest digital competence should be replaced with digital literacy in educational contexts since digital competence pays more attention to the ethical, safety, and social dimension (Foulger et al., 2017; Lund et al., 2014) and identifies more diverse knowledge, abilities, and desires of individuals (Falloon, 2020).

Despite the importance of digital competence, so far, only a few studies have investigated the role of students' digital competence in their DIL experiences. For example, Han and Yi (2019), examined the effects of higher education students' digital competence and technology expectancy and how these two interact with cultural differences on DIL. Their results highlighted the essential role of digital competence and technology expectancy in DIL. Moreover, they showed that students' cultural differences play a mediating role in the relationship between their digital competence and DIL behaviors. Pagani et al. (2016), in their study with secondary school students, reported that digital competence had a positive impact on students' academic performance. However, these studies have been conducted separately, and to our knowledge, no study has yet investigated the role of digital competence in both their DIL and academic performance, especially with the focus on higher education students.

As a result, the primary purpose of this study was to investigate the mediating role of DIL between digital competence and academic performance. Based on the reviewed literature (e.g., Baker, 2014; He \& Li, 2019; He \& Zhu, 2017; Hubbard, 2019; Mangiri et al., 2019), we postulated that there might be an asymmetric relationship between these three constructs. Thus, we first dive into the related literature to formulate different hypotheses related to the key constructs of the study. Afterward, these hypotheses are analysed by structural equation modeling for revealing possible relationships.

\section{Research hypotheses and model}

\subsection{Digital informal learning and academic performance}

Learning can occur in a formal or informal context. According to Meyers et al. (2013), formal learning occurs in a structured and organized educational environment and is explicitly designed in terms of time, objectives, and resources. From the learner's perspective, formal learning is intentional, which leads to degrees and certifications (Czerkawski, 2016). In contrast, informal learning occurs relatively in an unstructured and unorganized environment, mostly outside the formal classroom, and it does not have an objective in terms of learning degrees (Czerkawski, 2016; Meyers et al., 2013). In informal learning settings, the control of learning is in the learner's hands (Callanan et al., 2011; Falk \& Dierking, 2002), allowing them to have more control over the opportunity to learn, selecting what to learn, and evaluating themselves than formal learning setting (He \& Li, 2019; Huang \& Oh, 2016; Laurillard, 2009). The use of these opportunities has increased with the entrance of technology into life, especially in educational fields, and has provided a platform for a new type of learning called DIL (Dron \& Anderson, 2014; Holland, 2019; Lai, 2017).

DIL has been defined as the unstructured technology-mediated learning opportunities in informal learning settings (He et al., 2018; Ungerer, 2016). One of the most common settings for DIL is the Internet that provides further opportunities for searching information and finding the answers to learners' problems (Lai, 2017). Similar to any learning behavior, DIL has different aspects, namely cognitive learning (CL), metacognitive learning (MCL), and social and motivational learning (SML) (He \& Li, 2019). Based on the cognitive aspect, learners manipulate digital media to learn mentally or physically (Mayer, 1998). MCL refers to the process of planning, organizing, storing knowledge, monitoring comprehension, and facilitating learning to perform cognitive tasks (Mayer, 1998; Vermunt, 1996). MCL influences various learning strategies that learners choose, such as recognizing what approaches are better for memorizing information (Taheri et al., 2020). In the case of DIL, learners should choose the most appropriate strategy or technology that provides a better learning opportunity for them (Vermunt, 1996). Finally, the social and motivational aspects respectively refer to the essential social interaction in the digital setting to collaboratively build new knowledge or getting motivated to learn (Vermunt, 1996; Mayer, 1998).

Previous research confirmed the positive effect of DIL on students' learning outcome (e.g., Lee \& Dressman, 2018), engagement (e. g., Pechenkina et al., 2017), and retention of domain-specific knowledge (e.g., Pechenkina et al., 2017; Sommerauer \& Müller, 2014) in different educational contexts. One of the students' learning outcomes is academic performance. Some previous studies reported a positive effect of informal learning experiences on students' academic performance (e.g., Baker, 2014; Cox, 2013; Sackey et al., 2015). However, other studies reported negative findings related to the effect of students' DIL experiences on their academic performance. For instance, some scholars showed that using social media such as Facebook for learning purposes had a negative effect on students' GPA (Junco, 2012b; Junco \& Cotten, 2012; Kirschner \& Karpinski, 2010) and negatively predicted their engagement scale scores (Junco, 
2012a). In the same vein, Alloway et al. (2013) findings indicated that young people who used Facebook for more than a year had higher scores in tests of verbal ability, working memory, and spelling compared to their peers who had used it for a shorter period; but there was no difference between these two groups for math and cognitive scores.

Therefore, by considering these contradictory findings and since, to date, no study has investigated the direct effect of DIL on higher education students' academic performance, the following hypothesis was formulated for this study:

H1. DIL has a positive effect on higher education students' academic performance.

\subsection{Digital competence, digital informal learning, and academic performance}

According to Ferrari (2012), people with digital competence can use digital media to search for information, and they can critique what they receive from cyberspace, and at the same time gain the ability to communicate with others using a variety of digital tools and applications such as mobile phones or social media. Thus, digital competence is a multi-dimensional ability that can include ICT knowledge, ethical awareness, and higher-order cognitive skills (Calvani et al., 2012). Scholars refer to various theoretical frameworks for digital competence in the literature (Van Laar et al., 2017). For instance, based on Carretero et al. (2017), the digital competence framework has gone through three periods (i.e., DigComp 1.0, 2.0, and 2.1). DigComp 2.1 includes 21 sub-competencies structured to improve citizens' digital competence, consisting of five dimensions: information and data literacy, communication and collaboration, digital content creation, digital safety, and problem-solving. Each of the 21 sub-competencies is accompanied by descriptors of eight proficiency levels as well as examples of the requisite knowledge, skills, and attitudes for these eight levels. This framework is designed for developing the citizens' digital competence (Carretero et al., 2017).

Calvani et al. $(2009,2012)$ also introduced a digital competence framework that includes three technical, cognitive, and ethical dimensions. The technical dimension means that the user can discover and deal with new problems and technology context in a flexible way. This dimension consisted of visual literacy, troubleshooting, and understanding technological concepts. The cognitive dimension means that the user can read, select, interpret, and evaluate data and information, considering the information's appropriateness and reliability. This dimension includes organizing and connecting textual and visual data, organizing structured data, and information research. The ethical dimension means the ability to interact constructively as well as the responsibility with other people in using technologies that consist of staying safe online and respect for others (Vieru et al., 2015). Similar to the DigComp framework, Calvani et al.'s (2012) digital competence framework also used Bloom's taxonomy of learning and described the knowledge, skills, and attitudes underlying digital competence in five areas of competence (Ferrari et al., 2014).

This study adopted Calvani et al.s (2012) digital competence framework for two reasons: Firstly, this framework is multidimensional, which shows that the concept of digital competence is non-linear and is a combination of abilities, cognitive, relational, and social skills. Secondly, this framework is interconnected, which means that it is dependent on other abilities or basic competencies (e.g., reading, problem-solving, logical, inferential, and metacognitive skills) that overlap with digital competence (Calvani et al., 2012).

Some scholars put a relatively high emphasis on the positive effect of students' digital competence on their learning and performance in digital formal learning environments (e.g., Elstad \& Christophersen, 2017; Martín \& Tyner, 2012; Nyikes, 2018). Scholars also claimed that digital competence could have a substantial role in optimizing DIL's positive effects on students' learning outcomes (e.g., Hatlevik, Guðmundsdóttir, \& Loi, 2015; He et al., 2018; Hubbard, 2019; Pogue, 2019). Besides, a considerable body of literature highlighted the importance of digital competence in learners' performance at different educational levels, such as for teachers (Mangiri et al., 2019), university faculty members (Yazon et al., 2019), and middle school students (Hatlevik, Ottestad, \& Throndsen, 2015).

In addition to the above-mentioned studies, there are various findings about the effect of ICT on academic performance. Some studies reported a positive relationship between the use of ICT and academic performance (e.g., Basri et al., 2018; Nketiah-Amponsah et al., 2017; Çakıroğlu et al., 2017). Other studies showed that moderate access and use of ICT could increase academic performance, but over-access to ICT resources, use, and interest in ICT was associated with declining academic performance (e.g., Gubbels et al., 2020; Park et al., 2014). Fraillon et al. (2019) reported that students' daily use of computers at home and experience with computers was consistently related to computer and information literacy. However, they found no clear relation between the use of ICT for school-related purposes and the computer and information literacy score. In another study, Fraillon et al. (2014) declared that higher ICT development index scores were typically associated with higher computer and information literacy scores across countries. However, in contrast to these findings, Peña-López (2015) reported that the most frequent pattern that emerged in the Programme for International Student Assessment's (PISA) data showed a weak or sometimes negative association between investment in ICT use and students' academic performance.

However, in general, empirical studies that have investigated the effect of higher education students' digital competence on their DIL are scarce, especially with regard to their academic performance (He et al., 2018; Meyers et al., 2013). Only a few studies investigated the in-direct effect of digital competence together with students' technology expectancy (He \& Li, 2019) and innovativeness and attitudes (He \& Zhu, 2017) on DIL outcomes and adoption. Therefore, by considering these research gaps and previous literature, the following hypotheses are formulated to be investigated in this study:

H2. Higher education students' digital competence has a positive effect on their DIL.

H3. Higher education students' digital competence has a positive effect on their academic performance. 


\subsection{The mediating role of digital informal learning}

The results of Kim et al.'s (2018) study confirmed the positive effect of learners' prior experiences of using technologies on acquiring digital competence and their willingness to use technologies. Similarly, Khalifeh et al. (2020) reported that higher education students with a personal computer, laptop, or tablet demonstrated higher levels of readiness for online learning environments in their study on higher education students. Therefore, this study puts forward the idea that DIL can moderate the probable relationship between students' digital competence and academic performance. In the sense that students' DIL can contribute to their academic performance in two ways, first by a direct effect on their new knowledge acquisition outside the formal classes, and second by improving their digital competence, which may further contribute to their academic performance and success. As a result, the following hypothesis can be formulated and will be investigated in the current study:

H4. DIL plays a mediating effect in the relationship between higher education students' digital competence and their academic performance.

The path diagram related to the hypothesis of this study is shown in Fig. 1.

\section{Method}

\subsection{Study design and sample}

This study was explanatory by nature. The study was conducted at Shiraz University, one of the largest comprehensive higher education institutes in Iran, in the academic year 2019-2020. Based on the Cochran formula for a finite population (see Cochran, 1977), 350 students were recruited to participate in this study with $95 \%$ confidence and a $5 \%$ error level, which was also determined as an adequate sample size based on Westland's (2010) formulas. Moreover, with the effect size of 0.18 , the desired statistical power level of 0.8 , the probability level of 0.05 , the number of latent variables of 3 , and the number of observed variables of 10 , the minimum sample sizes for the AMOS structural equation modeling analysis was calculated to be 156, which was much smaller than our sample size of 350 respondents. The recruited students were required to answer the questionnaires through a stratified sampling method that the marker variables were level of degree and fields of study. However, only 319 questionnaires were returned, which indicated that the response rate was $91 \%$. As nonresponding participants were randomly distributed in different levels of degree and fields of study, the obtained data set was not biased. Table 1 shows the demographic information of the samples.

\subsection{Data analyses}

The SPSS data analysis software (version 22) was used to examine the validity of the instruments and also to provide descriptive analysis of the data. For structural equation modeling and also for model fitness, the AMOS module (version 21.0) was used. According to Lei and Wu (2007), one of AMOS's capabilities is producing bootstrapped standard error estimates, together with the maximum likelihood estimation method. The maximum likelihood method to estimate the model's parameters was also adopted in the current study, where all analyses were conducted on variance-covariance matrices (see Hair et al., 1998). Besides, to evaluate the overall fit of the model, several recommended indices were calculated in the present study: chi-square statistic $\left(\chi^{2}\right), \chi^{2} / \mathrm{df}$ ratio, the incremental fit index (IFI), the comparative fit index (CFI) (Hooper et al., 2008), and the root-mean- square error of approximation (RMSEA) (Browne \& Cudeck, 1989; Hooper et al., 2008). The acceptable threshold level of the model fit indicators is different in the various resources. For example $\chi 2 / \mathrm{df}$ ratio $<3$, IFI and CFI $>0.90$, RMSEA $<0.08$, SRMR $<0.10$ (Browne \& Cudeck, 1989; Hair, 2010); SRMR $<0.08$ and CFI $>0.95$ and SRMR < 0.08 (Hooper et al., 2008; Kline, 2015); RMSEA < 0.07 (Hooper et al., 2008) and RMSEA < 0.05 (Kline, 2015 ). As a result, CFI between 0.90 and 0.95 , RMSEA between 0.05 and 0.08 , SRMR between 0.08 and 0.10 , and RMSEA between 0.05 and 0.08 , and CFI between 0.90 and 0.95 indicates the adequate level for the current study. For mediation analyses, we used bootstrapping with 2000 bootstrap resamples to examine indirect effects in mediation models. Confidence intervals that do not contain zero indicate a significant indirect effect (mediation).

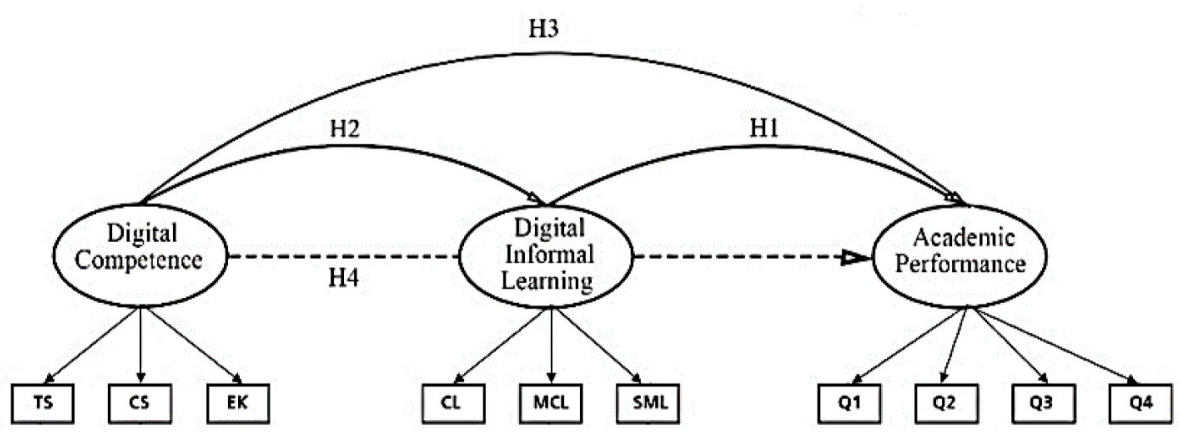

Fig. 1. Path diagram related to the study hypothesis. 
Table 1

Characteristics of the sample.

\begin{tabular}{|c|c|c|c|}
\hline Items & Categories & Number & Percentage \\
\hline \multirow[t]{2}{*}{ Gender } & Male & 181 & 56.7 \\
\hline & Female & 138 & 43.3 \\
\hline \multirow[t]{3}{*}{ Level of degree } & Undergraduate & 186 & 58.3 \\
\hline & Master & 89 & 27.9 \\
\hline & Ph.D & 44 & 13.8 \\
\hline \multirow[t]{3}{*}{ Fields of study } & Social sciences and humanities & 162 & 50.8 \\
\hline & engineering & 94 & 29.5 \\
\hline & Basic sciences & 63 & 19.7 \\
\hline
\end{tabular}

\subsection{Measures}

\subsubsection{Digital competence}

The instrument designed by He and Zhu (2017) was used to measure students' digital competence. He and Zhu (2017) developed this questionnaire based on Calvani et al.'s (2012) digital competence framework. This instrument includes three dimensions, i.e., technical skills (TS), cognitive skills (CS), and ethical knowledge (EK). The TS dimension includes 11 items (q1 to q11) related to the basic technological skills of students, such as "I can use some software programs to deal with data visualization." The CS dimension also includes 12 items (q12 to q23) regarding the needed cognitive skills for using technology, such as "I have a strong awareness of reliability of information when searching online." Finally, the EK dimension consists of 6 items (q24 to q29) related to the ethical issues of using technology, for instance, "When I deal with online payment, I am always aware of the safety issue." Each item includes 5-point Likert scale ( 1 = strongly disagree; 5 = strongly agree).

Questionnaire designers with different colleagues in the various studies have examined and confirmed the questionnaire's validity, especially by convergent and discriminant validity (He et al., 2018, 2020; He \& Li, 2019; He \& Zhu, 2017). In this study, the instrument validity was also examined by calculating the confirmatory factor analysis (CFA). Based on Buyukozturk (2007), the substance's factor load must be at 0.30 and above. Therefore, six items, i.e., q10, q18, q24, q26, and q27, were removed from the scale since their factor loads were below 0.30 . After eliminating the items, the analysis scale and its dimensions were rebuilt. Finally, factor loadings of TS items were between 0.31 and 0.73 ; CS items were between 0.35 and 0.75 , and EK items were between 0.47 and 0.80 . Therefore, each dimension was formed based on its remaining items' average scores after removing the low score items. Furthermore, the fit index of the scale was as follows: $\chi 2=577.02, \mathrm{df}=254$, P-value $=0.0001, \chi 2 / \mathrm{df}=2.27, \mathrm{IFI}=0.90, \mathrm{CFI}=0.90, \mathrm{RMSEA}=0.06$ and SRMR $=$ 0.01 .

In addition, the reliability of the instrument was estimated according to the CFA. The overall reliability of the instrument was calculated, and Cronbach's alpha value was 0.90. The calculated Cronbach's alpha of each dimension, i.e., TS (0.84), CS (0.83), and EK (0.80), confirmed the high reliability of this instrument for measuring students' digital competence. Also, the composite reliability (CR) for each dimension was obtained: TS (0.83), CS (0.83), and EK (0.73). These high composite reliability scores were above the critical value recommended by scholars (e.g., Hair et al., 1998).

\subsubsection{Digital informal learning}

He and Li's (2019) questionnaire was used to measure students' DIL. This questionnaire included three dimensions, i.e., CL, SML, and MCL. The CL dimension included four items related to the cognitive goals of using digital technologies in informal learning, such as "I often use digital technologies to engage in self-expression." The CL dimension was formed based on the average scores of q1 to q4. The SML dimension included four items related to the social and motivational goals of using technologies in informal learning, such as "I often use digital technologies to engage in constructive activities." and was formed based on the average scores of q9 to q12. Finally, the MCL dimension consisted of 4 items that measure DIL's meta-cognitive aspects, such as "I often use digital technologies to expand learning opportunities." The MCL dimension was formed based on the average scores of q5 to q8.

The questionnaire's validity have been confirmed in various studies by questionnaire designers and their colleagues (He et al., 2018, 2020; He \& Li, 2019; He \& Zhu, 2017). In addition, the reliability of this tool has also been investigated in different cultures. For example, in China, the Cronbach's alpha for CL, SML, and MCL, were 0.89, 0.89, and 0.90, and in Belgium, they were 0.79, 0.80, and 0.83 respectively (see $\mathrm{He} \& \mathrm{Li}, 2019$ ). In the current study, the validity of the instrument was examined by calculating CFA. Factor loadings of CL items were between 0.46 and 0.79 , SML items were between 0.48 and 0.77, and MCL items were between 0.64 and 0.83 . The fit index of the scale was as follows: $\chi 2=129.60, \mathrm{df}=49, \mathrm{P}$-value $=0.0001, \chi 2 / \mathrm{df}=2.64, \mathrm{IFI}=0.95, \mathrm{CFI}=0.95, \mathrm{RMSEA}=0.07$ and SRMR $=0.04$. The reliability of the instrument was examined according to the CFA by calculating the Cronbach's alpha. Cronbach's alpha coefficients for DIL was 0.89 , and for its diminutions were CL (0.75), SML (0.82), and MCL (0.78). Moreover, the values of CR for each dimension respectively were obtained: CL (0.72), SML (0.82), and MCL (0.74), which was above 0.70 .

\subsubsection{Academic performance}

Students' academic performance has been measured differently in literature. Some studies measured academic performance by students' grade point average or GPA (e.g., Kirschner \& Karpinski, 2010; Lau, 2017). Others measured academic performance by students' self-reported data such as students' perception of their ability to learn, perform academic tasks and their overall academic performance (e.g., Chang et al., 2019; El Ansari et al., 2020; Escalante Mateos et al., 2021; Han \& Yi, 2019; Martin et al., 2005; 
Richardson et al., 2005). In this study, academic performance was also measured by students' self-perception using Yu et al.'s (2010) questionnaire. This instrument included four items of students' academic performance, such as "I have learned how to perform my coursework efficiently successfully." The validity of this instrument has also been examined and confirmed in various studies (Nkhoma et al., 2015; Yu et al., 2010; Zhou, 2017). The validity of the instrument was also examined in the current study by calculating CFA. Factor loadings of items were between 0.50 and 0.86 . The fit index of the scale was as follows: $\chi 2=6.5, \mathrm{df}=2, \mathrm{P}$-value $=0.03, \chi 2 / \mathrm{df}=$ 3.25 , IFI $=0.90, \mathrm{CFI}=0.90, \mathrm{RMSEA}=0.08$ and $\mathrm{SRMR}=0.02$. According to the CFA, the reliability of this instrument was confirmed in the present study (Cronbach's $\alpha=0.86$ ). Also, the value of CR was obtained 0.82 , which was above 0.70 .

\section{Results}

\subsection{Preliminary analyses}

Table 2 demonstrates the means, standard deviations, skewness, kurtosis, Cronbach's alpha, and correlations between all the research variables. The means scores of digital competence dimensions ranged from 3.39 to 3.45, the means scores of DIL dimensions ranged from 3.68 to 3.76 , and the mean score of academic performance was 3.44, which were higher than the average level (3) based on a 5-point Likert scale, and they were in the third quartile (Q3). The standard deviations ranged from 0.68 to 0.82 . Skewness and kurtosis were used to check the normality of the constructs. All variables satisfied skewness (below 2) and kurtosis (below 7) as a multivariate normal distribution (Hu \& Bentler, 1999). These findings revealed that the model was suitable for SEM analysis. There was a positive correlation between the dimensions of the DIL variables, the dimensions of the digital competence variables, and academic performance.

\subsection{Measurement model}

We evaluated construct reliability and convergent validity for the measurement model. Appendix 1 provides information on the reliability and convergent validity, showing that the first- and second-order measurement models are correct. Construct reliability was assessed with CR. Cronbach's alpha and CR values were above the threshold value of 0.70 (Fornell \& Larcker, 1981). For the first-order measurement model, the CR values ranged from 0.75 to 0.89 , which were above 0.70 . The Cronbach's alphas of all variables were higher than 0.86 , which were above the suggested value of 0.70 . The convergent validity of the measurement model was also calculated by confirmatory factor analyses. The results showed that the factor loadings dimensions of the latent variables (digital competence, DIL, and academic performance) on the measurement model ranged from 0.51 to 0.89 . The fit index of this model was sufficient, as well $(\chi 2=67.80, \mathrm{df}=32$ P-value $=0.0001, \chi 2 / \mathrm{df}=2.11$, IFI $=0.97, \mathrm{CFI}=0.97, \mathrm{RMSEA}=0.05$ and SRMR $=0.05$ )."

In the second-order, latent variables such as TS, CS, EK, CL, MCL, and SML were specified with all of their underlying items. For these variables, the $\mathrm{CR}$ values ranged from 0.72 to 0.83 . Cronbach's alpha of all constructs was above 0.75 . The convergent validity of the second-order latent variable was calculated by confirmatory factor analyses. The result showed that the factor loadings of the latent variables were significant as follows: For the digital competence variable, the TS dimension $0.33-0.75$, the CS dimension $0.43-0.73$, and the EK dimension 0.61-0.75, for the DIL variable, the CL dimension 0.48-0.78, the MCL dimension 0.62-0.84, and the ML dimension 0.48-0.76, and finally for the academic performance items were between 0.52 and 0.83. Based on Buyukozturk (2007), the factor load of the substance needs to be at 0.30 and above. Therefore, five items of TS and EK dimensions (q10, q18, q24, q26, and q27) were removed (see Appendix 1). The fit index of this model was also good $(\chi 2=1267.37, \mathrm{df}=696 \mathrm{P}$-value $=0.0001, \chi 2 / \mathrm{df}=1.82, \mathrm{IFI}$ $=0.90$, CFI $=0.90$, RMSEA $=0.05$ and SRMR $=0.07$ ).

\subsection{Structural model}

We analysed the structural model to investigate the research hypotheses. As hypothesized, the structural model offered a good fit to the data $(\chi 2=46.130, p=0.0001 ; \chi 2 / \mathrm{df}=1.53$; IFI $=0.98 ; \mathrm{CFI}=0.98$; RMSEA $=0.04 ; \mathrm{SRMR}=0.036)$. The findings indicated that increasing DIL had a positive effect on improving students' academic performance $(\beta=24, p=0.0001)$, which confirmed our first research hypothesis (i.e., H1). The findings also showed that increasing students' digital competence had a positive and significant effect on increasing DIL ( $\beta=0.59, p=0.0001$ ), which confirms the second hypothesis (i.e., H2). Moreover, the results of the analysis showed that increasing students' digital competence had a positive effect on improving their academic performance $(\beta=0.46, p=$ 0.0001). So, the third hypothesis of the study, i.e., H3, was also confirmed. Table 3 demonstrates the summary of the direct, indirect,

Table 2

Means, standard deviations, correlations, and reliabilities.

\begin{tabular}{|c|c|c|c|c|c|c|c|c|c|c|c|}
\hline Variables & M & SD & Skew & Kurt & 1 & 2 & 3 & 4 & & 6 & 7 \\
\hline 1. TS & 3.39 & 0.71 & -0.24 & 0.08 & $(0.84)$ & & & & & & \\
\hline 2. CS & 3.45 & 0.70 & 0.50 & 2.8 & $0.67 * *$ & $(0.83)$ & & & & & \\
\hline 3. EK & 3.67 & 0.76 & -0.69 & 0.70 & $0.37 * *$ & $0.43^{* *}$ & $(0.80)$ & & & & \\
\hline 4. CL & 3.68 & 0.68 & -0.64 & 1.5 & $0.23^{* *}$ & $0.34 * *$ & $0.29 * *$ & $(0.75)$ & & & \\
\hline 5. MCL & 3.76 & 0.69 & -0.62 & 1.2 & $0.27 * *$ & $0.34 * *$ & $0.30 * *$ & $0.64 * *$ & $(0.82)$ & & \\
\hline 6. SML & 3.68 & 0.74 & -0.59 & 0.97 & $0.23^{* *}$ & $0.31^{* *}$ & $0.25^{* *}$ & $0.57^{* *}$ & $0.66^{* *}$ & $(0.78)$ & \\
\hline 7. Academic performance & 3.44 & 0.82 & -0.50 & 0.11 & $0.28^{* *}$ & $0.39 * *$ & $0.37^{* * *}$ & $0.45^{* *}$ & $0.33^{* *}$ & $0.33^{* *}$ & $(0.86)$ \\
\hline
\end{tabular}


Table 3

The summary of direct, indirect, and total effect of proposed relationships.

\begin{tabular}{|c|c|c|c|c|}
\hline $\mathrm{H} \#$ & Proposed Relationship & Direct Effect & Indirect Effect & Total Effect \\
\hline $\mathrm{H} 1$ & $\stackrel{\mathrm{DIL}}{\longrightarrow}$ Academic performance & 0.24 & - & 0.24 \\
\hline $\mathrm{H} 2$ & $\begin{array}{l}\text { Digital Competence } \\
\longrightarrow \text { DIL }\end{array}$ & 0.59 & - & 0.59 \\
\hline H3 & $\begin{array}{l}\text { Digital Competence } \\
\longrightarrow \text { Academic performance }\end{array}$ & 0.46 & - & 0.46 \\
\hline $\mathrm{H} 4$ & $\begin{array}{l}\text { Digital Competence } \\
\longrightarrow \text { DIL Academic }\end{array}$ & 0.46 & 0.14 & 0.60 \\
\hline
\end{tabular}

and total effect of proposed relationships.

\subsection{Mediation analyses}

The Bootstrap method with 2000 resamples was used to investigate the mediating effect and the indirect effect of DIL in the relationship between students' digital competence and their academic performance. The bootstrap method was used since it has been advocated in recent methodological publications as the preferred approach to mediation analysis, especially in the case of large samples (see Hayes et al., 2011; Rungtusanatham et al., 2014; Zhao et al., 2010). The results showed that the direct effect of digital competence on increasing academic performance was $\beta=0.46, p=0.0001$. The indirect effect of digital competence on increasing students' academic performance with mediating role of DIL was $\beta=0.14$, wherein the CI was between the range of $0.01-0.23$, and the 95\% CI did not include zero. This result indicates that the indirect effect between digital competence and academic performance through DIL is significant.

After including DIL as an intermediate variable, the association between digital competence and academic performance was reduced, but it still remained significant. This shows that DIL partially mediated the effect of digital competence on academic performance; hence hypothesis H4 was supported. The indirect effect of digital competence on academic performance through DIL was significant. Thus, considering the confirmation of the research hypotheses and the significant effects of the research variables on each other, it can be concluded that the proposed research model was approved as the final model (see Fig. 2).

\section{Discussions}

This study aimed to identify the mediating role of DIL between higher education students' digital competence and academic performance. In general, the study results indicated that DIL has a positive effect on students' academic performance. The analysis also confirmed that digital competence has a significant positive effect on students' DIL and academic performance. Moreover, DIL experiences contributed to students' academic performance in two ways, (1) by a direct effect on their performance and (2) by improving their digital competence.

According to the first hypothesis, the findings showed that the DIL has a positive effect on higher education students' academic performance. Thus, we can argue that DIL environments can better enable students to seek learning strategies, monitoring their learning progress, expanding their learning opportunities, and acquiring comprehensive knowledge. Therefore, these environments can genuinely improve students' academic performance besides their academic classes. In the same line, Petrovic (2019) pointed out that an important part of human life learning takes place outside the educational system, unintentionally, and through digital

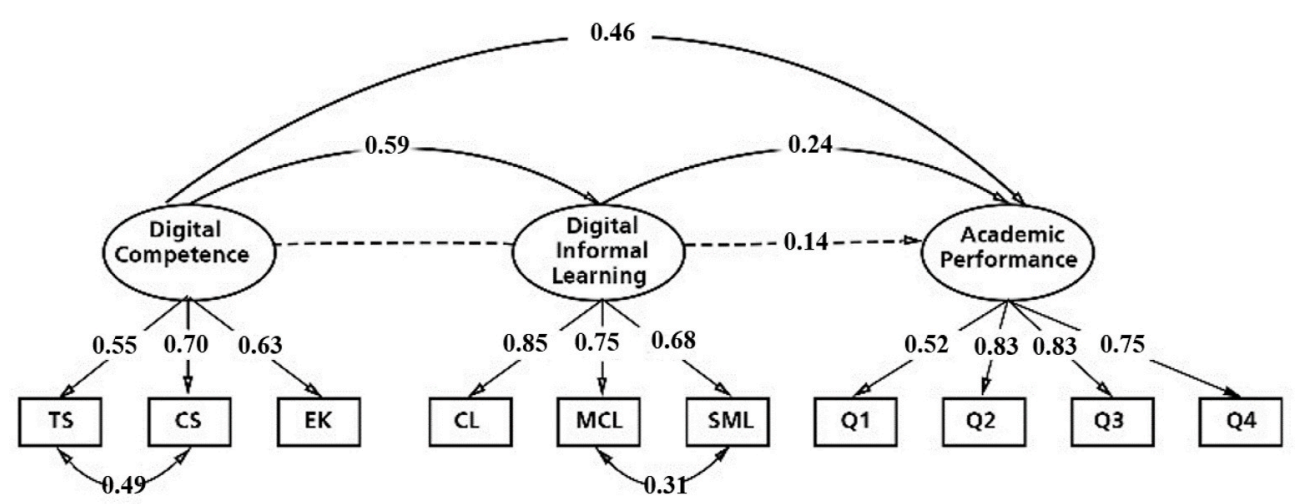

Fig. 2. Path analysis depicting direct and indirect effects of variables on each other. 
technologies. The finding of this study is also in line with previous studies for different learning outcomes and educational contexts (Trinder, 2017). For example, Huang and Oh (2016) reported that Internet-based informal learning could affect students' learning and academic performance and facilitate their decision-making processes. Also, Chang et al. (2019) showed in their studies, students with higher academic performance are more likely to use the Internet to relax or reduce their study load with less science but entertainment. Furthermore, they argued that DIL sustains students' motivation in learning, engages them in constructive activities, and teaches them how to perform their coursework successfully. Lee and Dressman (2018) showed that participation in a variety of DIL of English activities significantly predicts students' English language proficiency. Their result also showed that participants' diverse use of DIL of English contributed to a higher rating of willingness and motivation toward learning English. Align with their finding, He and Li (2019) argue that Deci and Ryan's (1985) self-determination theory can serve as a theoretical basis for DIL. According to self-determination theory, there is a positive link between the facilitation of a certain degree of autonomy and the degree of engagement and motivation that learners feel (Proulx et al., 2017). The autonomy that DIL provides for the students (see He \& Zhu, 2017) will ultimately increase their engagement with the learning goals and process, which this engagement will then contribute to their academic performance (Lee, 2014). Therefore, not only formal learning but also DIL can improve students' academic performance in one way or another.

Regarding our second hypothesis, the findings showed a positive and significant effect of digital competence on students' DIL, in the sense that the higher the competencies of students, the better they will be able to learn and achieve their goals in DIL. This result is consistent with the previous studies (Elstad \& Christophersen, 2017; Martín \& Tyner, 2012; Nyikes, 2018). Jin et al. (2019), in their review study related to the adults' informal learning using mobile devices, concluded that adults learn more from informal learning supported with mobile technology since it enables them to access content and make more interactions at any time and place according to their preferences. Also, considering the mediating effect of DIL, the more students use DIL opportunities, the higher their digital competencies, which further contribute to their academic performance. Students' positive prior digital experience significantly influences their digital competence and their attitude toward using digital technologies for educational purposes (Kim et al., 2018).

Similar to the previous hypotheses, the result of this study confirmed our third hypothesis, indicating that when students' digital competence is improved, their academic performance will also be improved. Many studies confirm the positive relationship between digital competence and academic performance in different educational contexts (Hatlevik, Ottestad, \& Throndsen, 2015; Kim et al., 2018; Mangiri et al., 2019; Yazon et al., 2019). For instance, in vocational high schools, Mangiri et al. (2019) reported that teachers' digital competence plays a decisive role in their professional development. Also, in higher education, students should improve their computer literacy skills in line with the rapid global digitalization. Acquiring digital competence allows students to obtain technical, cognitive, and ethical skills and knowledge. Also, digital competence helps students design their plan or schedule related to their scientific needs, solve software problems by searching online, communicate rationally with others online, and find the answer to their scientific questions and problems with the help of their digital competence.

\section{Conclusion, limitations, and implications}

The results of this study showed positive mediating role of DIL in the relationship between students' digital competence and their academic performance. Although digital competence has a direct positive effect on students' academic performance, together with DIL experiences, it yields a greater effect on their performance in their formal classes. Since the DIL plays a mediating role in the relationship between students' digital competence and their academic performance, digital competence can directly affect academic performance, as well.

Despite the important result of this study for higher education, several limitations of this study should be acknowledged. In this study, similar to other studies (Aesaert et al., 2017; Chang et al., 2019; El Ansari et al., 2020; Escalante Mateos et al., 2021; Han \& Yi, 2019; Martin et al., 2005; Richardson et al., 2005), we used self-reported data for measuring students' digital competence and their academic performance. Aesaert et al. (2017) shows that students make accurate judgments about their ability in digital information processing and communication, meaning that the magnitude of students' judgment error of their competencies is not big. However, students in self-reported measurement instruments may have a bias regarding their experiences. For example, they may provide responses that are socially acceptable in such self-reported instruments (Devaux \& Sassi, 2016). Next to social desirability, in self-reported measurements, over-confident students may overestimate their competencies as opposed to less-confident students who may underestimate their competencies (see Aesaert et al., 2017; Noroozi et al., 2013). Therefore, in order to deal with the flaws that are inherent to self-reported measurements, we suggest future studies to use both self-reported and actual performance tests simultaneously to find out the extent to which the findings of self-reported data (perceived academic performance) are in line with the actual performance (real academic performance) of students.

Another important limitation is the methodology of the current study. This study focused on the complex relationships between various research variables using structural equation modeling without any empirical intervention. Therefore, future research can focus on specific strategies, for example, for developing students' digital competence and DIL to investigate their effects on students' academic performance in empirical settings. Also, some research can explore the strategies that can make students use DIL.

Based on the findings of this study, in this digitalization age, educators and educational policy-makers should pay more attention to promoting and improving students' digital competencies in order to enhance their academic performance. Also, as students have more flexibility and control over their learning in DIL settings, university policy-makers should pay attention to informal learning contexts alongside formal learning. Also, in order to improve students' academic performance, higher education institutions, educators and curriculum designers should not only improve the students' digital competence through extra-curricular programs (Basantes-Andrade et al., 2020), but also should provide opportunities for students to learn outside the formal classes through digital environments. 


\section{Credit author statement}

The authors would like to thank you for your time and careful review on our article CAE-D-20-01164, "The Mediating Role of Digital Informal Learning in the Relationship between Students' Digital Competence and their Academic Performance.” I ensure that all the authors (Mahboobe Mehrvarz, Elham Heidari, Mohammadreza Farrokhnia \& Omid Noroozi) had the same role in Conceptualization, Methodology, Software, Data curation, writing- Original draft preparation, etc. Thanks again for reviewing our manuscript.

\section{Funding}

The authors received no financial support for this article.

\section{Acknowledgments}

The authors would like to thank all the students of Shiraz University who have participated on this study.

\section{Appendix 1. Confirmatory factor analysis}

\begin{tabular}{|c|c|c|c|}
\hline factor & loadings & Cronbach's alpha & $\mathrm{CR}$ \\
\hline Digital competence & & 0.90 & 0.76 \\
\hline TS $\quad 0.75$ & & 0.84 & 0.83 \\
\hline I can use some software programs to deal with data visualization & 0.33 & & \\
\hline I can use a certain software program to edit pictures & 0.57 & & \\
\hline I can use a certain software program to make video & 0.57 & & \\
\hline I can use a variety of programs to deal with Antivirus problem for computer & 0.68 & & \\
\hline I can deal with computer system problems & 0.72 & & \\
\hline I can deal with software problems by searching online & 0.75 & & \\
\hline I can use at least one operating system skillfully (e.g., Windows, OSX, Android, IOS, etc.) & 0.70 & & \\
\hline I am able to operate at least a personal computer-related hardware (desktop, laptop, tablet device or smartphone device) & 0.57 & & \\
\hline I am able to use social media well & 0.43 & & \\
\hline I am able to use some photo and video sharing tool well & - & & \\
\hline I am able to use a variety of APPs & 0.42 & & \\
\hline CS $\quad 0.89$ & & 0.83 & 0.83 \\
\hline I can represent a text with a graph by digital tools & 0.71 & & \\
\hline I can represent hierarchical classes with digital tools & 0.69 & & \\
\hline I can identify the keywords well in a digital text very well & 0.70 & & \\
\hline I can organize data in a table by a variety of digital tools & 0.73 & & \\
\hline I can find missing values in a table of digital context & 0.43 & & \\
\hline I can use digital technologies to design my plan or schedule & 0.57 & & \\
\hline I am quite confident at searching for information online what I need & - & & \\
\hline I am quite confident at searching for information on a certain database & 0.43 & & \\
\hline I have a strong awareness of the credibility of information when search online & 0.47 & & \\
\hline I have a strong awareness of the reliability of information when search online & 0.56 & & \\
\hline I often consider the reliability of information online when I quote or share it & 0.43 & & \\
\hline I often consider the credibility of information online when I quote or share it & 0.57 & & \\
\hline EK & 0.51 & 0.80 & 0.73 \\
\hline When I surf online, I have awareness of Privacy (personal information, personal Photos, etc.) & - & & \\
\hline When I deal with online payment, I am always aware of the safety issue & 0.75 & & \\
\hline When I see online content that makes me feel uncomfortable, unsafe or worried, I will leave it or take an action & - & & \\
\hline I often post pictures with my friends on the Internet without their permission (reverse) & - & & \\
\hline I have an awareness of online bullying and behave myself decent online & 0.65 & & \\
\hline I have the awareness to comment or communicate with others online in a rational way & 0.61 & & \\
\hline Digital Informal Learning & & 0.89 & 0.83 \\
\hline CL $\quad 0.77$ & & 0.75 & 0.72 \\
\hline I often use digital technologies to enhance my understanding of school course materials in informal learning contexts & 0.62 & & \\
\hline I often use digital technologies to expand knowledge of the discipline & 0.72 & & \\
\hline I often use digital technologies to keep informed of the development in the discipline & 0.78 & & \\
\hline I often use digital technologies to engage in self-expression & 0.48 & & \\
\hline MCL $\quad 0.84$ & & 0.82 & 0.74 \\
\hline I often use digital technologies to seek learning strategies and tips & 0.62 & & \\
\hline I often use digital technologies to help myself to monitor learning progress & 0.74 & & \\
\hline I often use digital technologies to expand learning opportunities & 0.84 & & \\
\hline I often use digital technologies to seek engaging learning experiences & 0.67 & & \\
\hline SML & 0.77 & 0.87 & 0.82 \\
\hline I often use digital technologies to sustain motivation in learning & 0.76 & & \\
\hline
\end{tabular}


(continued)

\begin{tabular}{lll}
\hline factor & Cronbach's alpha & CR \\
\hline I often use digital technologies to elicit support and help & 0.73 \\
I often use digital technologies to engage in constructive activities & 0.62 & 0.48 \\
I often use digital technologies to collaborate with people for learning & 0.86 \\
\hline Academic Performance & 0.52 \\
I am confident about the adequacy of my academic skills and abilities & 0.83 \\
I feel competent conducting my course assignments & 0.83 \\
I have learned how to perform my coursework in an efficient manner successfully & 0.75 \\
I have performed academically as well as I anticipated I would & \\
\hline
\end{tabular}

\section{References}

Aesaert, K., Voogt, J., Kuiper, E., \& van Braak, J. (2017). Accuracy and bias of ICT self-efficacy: An empirical study into students over-and underestimation of their ICT competences. Computers in Human Behavior, 75, 92-102.

Ali, P. A., \& Naylor, P. B. (2010). Association between academic and non-academic variables and academic success of diploma nursing students in Pakistan. Nurse Education Today, 30(2), 157-162.

Alloway, T. P., Horton, J., Alloway, R. G., \& Dawson, C. (2013). The impact of technology and social networking on working memory. Computers \& Education, 63, $10-16$.

Ang, S. S., Orozco, M., Gijbels, D., \& Van den Bossche, P. (2018). Learning in the context of work in a digital age: The use of digital media in informal and formal learning contexts. The impact of digitalization in the workplace. Springer.

Baker, F. (2014). Reflections on an informal learning environment with invocations for classroom learning in Dubai, the United Arab Emirates. International Journal of Adolescence and Youth, 19(1), 50-66. https://doi.org/10.1080/02673843.2012.699880

Basantes-Andrade, A., Cabezas-González, M., \& Casillas-Martín, S. (2020). Digital competences relationship between gender and generation of university professors. International Journal of Advanced Science, Engineering and Information Technology, 10(1), 205-211. https://doi.org/10.18517/ijaseit.10.1.10806

Basri, W. S., Alandejani, J. A., \& Almadani, F. M. (2018). ICT adoption impact on students' academic performance: Evidence from Saudi universities. Education Research International. https://doi.org/10.1155/2018/1240197

Browne, M. W., \& Cudeck, R. (1989). Single sample cross-validation indices for covariance structures. Multivariate Behavioral Research, 24(4), 445-455. https://doi. org/10.1207/s15327906mbr2404_4

Buyukozturk, S. (2007). Sosyal bilimler için veri analizi el kitabi, Handbook of data analysis for social sciences. Pegem A Pub.

Çakıroğlu, Ü., Başıbüyük, B., Güler, M., Atabay, M., \& Yılmaz Memiş, B. (2017). Gamifying an ICT course: Influences on engagement and academic performance. Computers in Human Behavior, 69, 98-107. https://doi.org/10.1016/j.chb.2016.12.018

Callanan, M., Cervantes, C., \& Loomis, M. (2011). Informal learning. Wiley Interdisciplinary Reviews: Cognitive Science, 2(6), 646-655. https://doi.org/10.1002/wcs.143

Calvani, A., Fini, A., \& Ranieri, M. (2009). Assessing digital competence in secondary education. Issues, models and instruments. Issues in information and media literacy: Education, practice and pedagogy.

Calvani, A., Fini, A., Ranieri, M., \& Picci, P. (2012). Are young generations in secondary school digitally competent? A study on Italian teenagers. Computers and Education, 58(2), 797-807. https://doi.org/10.1016/j.compedu.2011.10.004

Carretero, S., Vuorikari, R., \& Punie, Y. (2017). DigComp 2.1: The digital competence framework for citizens with eight proficiency levels and examples of use. Publications Office of the European Union.

Chang, C. T., Tu, C. S., \& Hajiyev, J. (2019). Integrating academic type of social media activity with perceived academic performance: A role of task-related and nontask-related compulsive Internet use. Computers \& Education, 139, 157-172.

Chan, N. N., Walker, C., \& Gleaves, A. (2015). An exploration of students' lived experiences of using smartphones in diverse learning contexts using a hermeneutic phenomenological approach. Computers and Education, 82, 96-106. https://doi.org/10.1016/j.compedu.2014.11.001

Cochran, W. G. (1977). Sampling techniques. John Wiley \& Sons.

Coll, S. D., \& Treagust, D. F. (2015). Using informal learning experiences to enhance student learning outcomes in chemistry. In I. Eilks, \& A. Hofstein (Eds.), Relevant chemistry education: From theory to practice (pp. 355-368). Sense Publishers. https://doi.org/10.1007/978-94-6300-175-5_19.

Cox, M. J. (2013). Formal to informal learning with IT: Research challenges and issues for e-learning. Journal of Computer Assisted Learning, 29(1), 85-105.

Czerkawski, B. C. (2016). Blending formal and informal learning networks for online learning. International Review of Research in Open and Distance Learning, 17(3), 138-156. https://doi.org/10.19173/irrodl.v17i3.2344

Deci, E. L., \& Ryan, R. M. (1985). Intrinsic motivation and self-determination in human behavior. In Intrinsic motivation and self-determination in human behavior. Springer Science \& Business Media. https://doi.org/10.1007/978-1-4899-2271-7.

Devaux, M., \& Sassi, F. (2016). Social disparities in hazardous alcohol use: Self-report bias may lead to incorrect estimates. The European Journal of Public Health, 26 (1), 129-134.

Doleck, T., Lajoie, S. P., \& Bazelais, P. (2019). Social networking and academic performance: A net benefits perspective. Education and Information Technologies, 24(5), 3053-3073.

Dron, J., \& Anderson, T. (2014). Teaching crowds: Learning and social media. Athabasca University Press. https://doi: 10.15215/aupress/9781927356807.01.

El Ansari, W., Salam, A., \& Suominen, S. (2020). Is alcohol consumption associated with poor perceived academic performance? Survey of undergraduates in Finland. International Journal of Environmental Research and Public Health, 17(4), 1369.

Elstad, E., \& Christophersen, K. A. (2017). Perceptions of digital competency among student teachers: Contributing to the development of student teachers' instructional self-efficacy in technology-rich classrooms. Education Sciences, 7, 19-35.

Escalante Mateos, N., Fernández-Zabala, A., \& Goñi Palacios, E. (2021). School climate and perceived academic performance: Direct or resilience-mediated relationship? Sustainability, 13(1), 68.

Falk, J. H., \& Dierking, L. D. (2002). Lessons without limit: How free-choice learning is transforming education. Rowman Altamira.

Falloon, G. (2020). From digital literacy to digital competence: The teacher digital competency (TDC) framework. Educational Technology Research \& Development, 68 (5), 2449-2472.

Farrokhnia, M., Pijeira-Díaz, H. J., Noroozi, O., \& Hatami, J. (2019). Computer-supported collaborative concept mapping: The effects of different instructional designs on conceptual understanding and knowledge co-construction. Computers \& Education, 142, 103640. https://doi.org/10.1016/j.compedu.2019.103640

Ferrari, A. (2012). Digital competence in practice: An analysis of frameworks.

Ferrari, A. (2013). Digcomp: A framework for developing and understanding digital competence in europe. Publications Office of the European Union Luxembourg. https:// doi.org/10.2788/52966

Ferrari, A., Brečko, B. N., \& Punie, Y. (2014). Digcomp: A framework for developing and understanding digital competence in europe. 7. Special Edition.

Fornell, C., \& Larcker, D. F. (1981). Evaluating structural equation models with unobservable variables and measurement error. Journal of Marketing Research, 18(1), 50. https://doi.org/10.2307/3151312 
Foulger, T. S., Graziano, K. J., Schmidt-Crawford, D., \& Slykhuis, D. A. (2017). Teacher educator technology competencies. Journal of Technology and Teacher Education, 25(4), 413-448.

Fraillon, J., Ainley, J., Schulz, W., Friedman, T., \& Duckworth, D. (2019). Preparing for life in a digital world: IEA international computer and information literacy study 2018 international report.

Fraillon, J., Ainley, J., Schulz, W., Friedman, T., \& Gebhardt, E. (2014). Preparing for life in a digital age. Preparing for life in a digital age. Springer. https://doi.org/ 10.1007/978-3-319-14222-7

Gubbels, J., Swart, N. M., \& Groen, M. A. (2020). Everything in moderation: ICT and reading performance of Dutch 15-year-olds. Large-Scale Assessments in Education, 8(1), 1. https://doi.org/10.1186/s40536-020-0079-0

Hair, J. F. (2010). Multivariate data analysis. Pearson Education International.

Hair, J., Black, W. C., Babin, B. J., \& Anderson, R. E. (1998). Multivariate data analysis. Prentice-Hall.

Han, S., \& Yi, Y. J. (2019). How does the smartphone usage of college students affect academic performance? Journal of Computer Assisted Learning, 35(1), 13-22.

Hassanzadeh, M., Hatami, J., Latifi, S., Farrokhnia, M. R., \& Saheb, T. (2016). Teaching science for understanding: The positive impact of simultaneous use of concept mapping and computer simulations. Communications in Computer and Information Science, 635, 192-202. https://doi.org/10.1007/978-3-319-45501-3_15

Hatlevik, O. E., Guðmundsdóttir, G. B., \& Loi, M. (2015). Examining factors predicting students' digital competence. Journal of Information Technology Education: Research, 14, 123-137. https://eric.ed.gov/?id=EJ1060150.

Hatlevik, O. E., Ottestad, G., \& Throndsen, I. (2015). Predictors of digital competence in 7th grade: A multilevel analysis. Journal of Computer Assisted Learning, 31(3), 220-231. https://doi.org/10.1111/jcal.12065

Hayes, A. F., Preacher, K. J., \& Myers, T. A. (2011). Mediation and the estimation of indirect effects in political communication research. In E. P. Bucy, \& R. L. Holbert (Eds.), Sourcebook for political communication research: Methods, measures and analytical techniques (pp. 434-465). Routledge.

He, T., Huang, Q., Yu, X., \& Li, S. (2020). Exploring students' digital informal learning: The roles of digital competence and DTPB factors. Behaviour and information technology. https://doi.org/10.1080/0144929X.2020.1752800

Heidari, E., Salimi, G., \& Mehrvarz, M. (2020). The influence of online social networks and online social capital on constructing a new graduate students professional identity. Interactive Learning Environments, 1-18. https://doi.org/10.1080/10494820.2020.1769682

He, T., \& Li, S. (2019). A comparative study of digital informal learning: The effects of digital competence and technology expectancy. British Journal of Educational Technology, 50(4), 1744-1758. https://doi.org/10.1111/bjet.12778

Helsper, E. J., van Deursen, A. J. A. M., Eynon, R., \& van Deursen, A. J. A. M. (2015). Tangible outcomes of Internet use: From digital skills to tangible outcomes project report. From Digital Skills to Tangible Outcomes Project Report, 1-72.

He, T., \& Zhu, C. (2017). Digital informal learning among Chinese university students: The effects of digital competence and personal factors. International Journal of Educational Technology in Higher Education, 14(1), 1-19. https://doi.org/10.1186/s41239-017-0082-x

He, T., Zhu, C., \& Questier, F. (2018). Predicting digital informal learning: An empirical study among Chinese university students. Asia Pacific Education Review, 19(1), 79-90. https://doi.org/10.1007/s12564-018-9517-x

Holland, A. A. (2019). Effective principles of informal online learning design: A theory-building metasynthesis of qualitative research. Computers \& Education, 128, $214-226$.

Hooper, D., Coughlan, J., \& Mullen, M. (2008). Structural equation modelling: Guidelines for determining model fit. Articles, 6(1), 53-60. https://doi.org/10.21427/ D7CF7R

Huang, W. H. D., \& Oh, E. (2016). Retaining disciplinary talents as informal learning outcomes in the digital age: An exploratory framework to engage undergraduate students with career decision-making processes. In V. C. X. Wang (Ed.), Handbook of research on learning outcomes and opportunities in the digital age (pp. 402-420). IGI Global.

Hubbard, P. (2019). Leveraging technology to integrate informal language learning within classroom settings. In M. Dressman, \& R. W. Sadler (Eds.), The handbook of informal language learning (pp. 405-419). John Wiley \& Sons Ltd.

Hu, L. T., \& Bentler, P. M. (1999). Cutoff criteria for fit indexes in covariance structure analysis: Conventional criteria versus new alternatives. Structural Equation Modeling, 6(1), 1-55. https://doi.org/10.1080/10705519909540118

Hung, H. P. (2005). Ethnicity, gender, and the academic performance of adolescents: An examination of the influence of culture. State University of New York at Buffalo. Ilomäki, L., Kantosalo, A., \& Lakkala, M. (2011). What is digital competence? Linked portal.

Iordache, C., Mariën, I., \& Baelden, D. (2017). Developing digital skills and competences: A quick-scan analysis of 13 digital literacy models. Italian Journal of Sociology of Education, 9(1), 6-30. https://doi.org/10.14658/pupj-ijse-2017-1-2

Janssen, J., Stoyanov, S., Ferrari, A., Punie, Y., Pannekeet, K., \& Sloep, P. (2013). Experts' views on digital competence: Commonalities and differences. Computers \& Education, 68, 473-481.

Jin, B., Kim, J., \& Baumgartner, L. M. (2019). Informal learning of older adults in using mobile devices: A review of the literature. Adult Education Quarterly, 69(2), 120-141. https://doi.org/10.1177/0741713619834726

Jin, K. Y., Reichert, F., Cagasan, L. P., Jr., de la Torre, J., \& Law, N. (2020). Measuring digital literacy across three age cohorts: Exploring test dimensionality and performance differences. Computers \& Education, 157, 103968.

Junco, R. (2012a). The relationship between frequency of Facebook use, participation in Facebook activities, and student engagement. Computers and Education, 58(1), 162-171. https://doi.org/10.1016/j.compedu.2011.08.004

Junco, R. (2012b). Too much face and not enough books: The relationship between multiple indices of Facebook use and academic performance. Computers in Human Behavior, 28(1), 187-198. https://doi.org/10.1016/j.chb.2011.08.026

Junco, R., \& Cotten, S. R. (2012). No A 4 U: The relationship between multitasking and academic performance. Computers and Education, 59(2), 505-514. https://doi. org/10.1016/j.compedu.2011.12.023

Jurkovič, V. (2019). Online informal learning of English through smartphones in Slovenia. System, 80, 27-37. https://doi.org/10.1016/j.system.2018.10.007

Khalifeh, G., Noroozi, O., Farrokhnia, M., \& Talaee, E. (2020). Higher education students' perceived readiness for computer-supported collaborative learning. Multimodal Technologies and Interaction, 4(2), 11. https://doi.org/10.3390/mti4020011

Kim, H., Hong, A., \& Song, H.-D. (2018). The relationships of family, perceived digital competence and attitude, and learning agility in sustainable student engagement in higher education. Sustainability, 10(12), 1-16. https://doi.org/10.3390/su10124635

Kirschner, P. A., \& Karpinski, A. C. (2010). Facebook $\mathbb{B}$ and academic performance. Computers in Human Behavior, 26(6), 1237-1245. https://doi.org/10.1016/j. chb.2010.03.024

Kline, R. B. (2015). Principles and practice of structural equation modeling. Guilford publications.

Lai, H. J. (2017). Factors affecting knowledge acquisition among adult workers in online informal learning activities. Eurasia Journal of Mathematics, Science and Technology Education, 14(1), 505-515.

Lau, W. W. (2017). Effects of social media usage and social media multitasking on the academic performance of university students. Computers in Human Behavior, 68, $286-291$.

Laurillard, D. (2009). The pedagogical challenges to collaborative technologies. International Journal of Computer-Supported Collaborative Learning, 4(1), 5-20. https:// doi.org/10.1007/s11412-008-9056-2

Lee, J.-S. (2014). The relationship between student engagement and academic performance: Is it a myth or reality? The Journal of Educational Research, 107(3), 177-185. https://doi.org/10.1080/00220671.2013.807491

Lee, J. S., \& Dressman, M. (2018). When idle hands make an English workshop: Informal digital learning of English and language proficiency. Tesol Quarterly, 52(2), 435-445. https://doi.org/10.1002/tesq.422

Lei, P. W., \& Wu, Q. (2007). Introduction to structural equation modeling: Issues and practical considerations. Educational Measurement: Issues and Practice, 26(3), 33-43. https://doi.org/10.1111/j.1745-3992.2007.00099.x 
Lund, A., Furberg, A., Bakken, J., \& Engelien, K. (2014). What does professional digital competence mean in teacher education? Nordic Journal of Digital Literacy, 9(4), 281-299.

Mangiri, H. S., Sofyan, H., Susanto, A., \& Rohmantoro, D. (2019). The contribution of teacher's digital competency to teacher's professionalism at vocational high school. International Journal of Innovative Technology and Exploring Engineering, 9(1), 1728-1731.

Martin, A., \& Grudziecki, J. (2006). DigEuLit: Concepts and tools for digital literacy development. Innovation in Teaching and Learning in Information and Computer Sciences, 5(4), 249-267. https://doi.org/10.11120/ital.2006.05040249

Martin, G., Richardson, A. S., Bergen, H. A., Roeger, L., \& Allison, S. (2005). Perceived academic performance, self-esteem and locus of control as indicators of need for assessment of adolescent suicide risk: Implications for teachers. Journal of Adolescence, 28(1), 75-87.

Martín, A. G., \& Tyner, K. (2012). Media education, media literacy and digital competence. Comunicar: Revista Científica de Comunicación y Educación, 19(38), 31-39.

Mayer, R. E. (1998). Cognitive, metacognitive, and motivational aspects of problem solving. Instructional Science, 26(1-2), 49-63.

Meyers, E. M., Erickson, I., \& Small, R. V. (2013). Digital literacy and informal learning environments: An introduction. Learning, Media and Technology, 38(4), 355-367. https://doi.org/10.1080/17439884.2013.783597

Mishra, S. (2020). Social networks, social capital, social support and academic success in higher education: A systematic review with a special focus on 'underrepresented'students. Educational Research Review, 29, 100307.

Mthimunye, K. D. T., \& Daniels, F. M. (2020). Exploring the challenges and efforts implemented to improve the academic performance and success of nursing students at a university in the Western Cape. International Journal of Africa Nursing Sciences, Article 100196.

Nketiah-Amponsah, E., Asamoah, M. K., Allassani, W., \& Aziale, L. K. (2017). Examining students' experience with the use of some selected ICT devices and applications for learning and their effect on academic performance. Journal of Computers in Education, 4(4), 441-460. https://doi.org/10.1007/s40692-017-00892

Nkhoma, M., Cong, H. P., Au, B., Lam, T., Richardson, J., Smith, R., \& El-Den, J. (2015). Facebook as a tool for learning purposes: Analysis of the determinants leading to improved students' learning. Active Learning in Higher Education, 16(2), 87-101. https://doi.org/10.1177/1469787415574180

Noroozi, O., Biemans, H., \& Mulder, M. (2016). Relations between scripted online peer feedback processes and quality of written argumentative essay. Internet and Higher Education, 31, 20-31. https://doi.org/10.1016/j.iheduc.2016.05.002

Noroozi, O., Biemans, H. J. A., Weinberger, A., Mulder, M., \& Chizari, M. (2013). Scripting for construction of a transactive memory system in a multidisciplinary CSCL environment. Learning and Instruction, 25(1), 1-12.

Noroozi, O., Hatami, J., Bayat, A., van Ginkel, S., Biemans, H. J. A., \& Mulder, M. (2018). Students' online argumentative peer feedback, essay writing, and content learning: Does gender matter? Interactive Learning Environments, 1-15. https://doi.org/10.1080/10494820.2018.1543200

Nyikes, Z. (2018). Contemporary digital competency review. Interdisciplinary Description of Complex Systems, 16(1), 124-131. https://doi.org/10.7906/indecs.16.1.9

Pagani, L., Argentin, G., Gui, M., \& Stanca, L. (2016). The impact of digital skills on educational outcomes: Evidence from performance tests. Educational Studies, 42(2), 137-162. https://doi.org/10.1080/03055698.2016.1148588

Park, S., Kang, M., \& Kim, E. (2014). Social relationship on problematic Internet use (PIU) among adolescents in South Korea: A moderated mediation model of selfesteem and self-control. Computers in Human Behavior, 38, 349-357. https://doi.org/10.1016/j.chb.2014.06.005

Pechenkina, E., Laurence, D., Oates, G., Eldridge, D., \& Hunter, D. (2017). Using a gamified mobile app to increase student engagement, retention and academic achievement. International Journal of Educational Technology in Higher Education, 14(1), 1-12. https://doi.org/10.1186/s41239-017-0069-7

Peña-López, I. (2015). Students, computers and learning. Making the connection.

Petrovic, O. (2019). Digital media and informal learning: Alteration mechanism and captured episodes. Proceedings of the 10th International Conference on Computer Supported Education, 321-330. https://doi.org/10.5220/0006772303210330

Pogue, M. (2019). Computer self-efficacy as an inherent characteristic of digital natives in online learning environments. (Doctoral dissertation). Northcentral University.

Proulx, J.-N., Romero, M., \& Arnab, S. (2017). Learning mechanics and game mechanics under the perspective of self-determination theory to foster motivation in digital game based learning. Simulation \& Gaming, 48(1), 81-97. https://doi.org/10.1177/1046878116674399

Reinders, H., \& Benson, P. (2017). Research agenda: Language learning beyond the classroom. Language Teaching, 50(4), 561-578. https://doi.org/10.1017/ S0261444817000192

Richardson, A. S., Bergen, H. A., Martin, G., Roeger, L., \& Allison, S. (2005). Perceived academic performance as an indicator of risk of attempted suicide in young adolescents. Archives of Suicide Research, 9(2), 163-176.

Rungtusanatham, M., Miller, J. W., \& Boyer, K. K. (2014). Theorizing, testing, and concluding for mediation in SCM research: Tutorial and procedural recommendations. Journal of Operations Management, 32(3), 99-113. https://doi.org/10.1016/j.jom.2014.01.002

Sackey, D. J., Nguyen, M. T., \& Grabill, J. T. (2015). Constructing learning spaces: What we can learn from studies of informal learning online. Computers and Composition, 35, 112-124. https://doi.org/10.1016/j.compcom.2015.01.004

Seo, K., Dodson, S., Harandi, N. M., Roberson, N., Fels, S., \& Roll, I. (2021). Active learning with online video: The impact of learning context on engagement. Computers \& Education, 165, 104132.

Sommerauer, P., \& Müller, O. (2014). Augmented reality in informal learning environments: A field experiment in a mathematics exhibition. Computers and Education, 79, 59-68. https://doi.org/10.1016/j.compedu.2014.07.013

Song, D., \& Lee, J. (2014). Has web 2.0 revitalized informal learning? The relationship between web 2.0 and informal learning. Journal of Computer Assisted Learning, 30(6), 511-533. https://doi.org/10.1111/jcal.12056

Taheri, H., Sadighi, F., Bagheri, M. S., \& Bavali, M. (2020). Investigating the relationship between Iranian EFL learners' use of language learning strategies and foreign language skills achievement. Cogent Arts \& Humanities, 7(1), 1710944

Trinder, R. (2017). Informal and deliberate learning with new technologies. ELT Journal, 71(4), 401-412. https://doi.org/10.1093/elt/ccw117

Ungerer, L. (2016). Digital curation as a core competency in current learning and literacy: A higher education perspective. International Review of Research in Open and Distance Learning: IRRODL, 17(5), 1-27.

Van Laar, E., van Deursen, A. J. A. M., van Dijk, J. A. G. M., \& de Haan, J. (2017). The relation between 21st-century skills and digital skills: A systematic literature review. Computers in Human Behavior, 72, 577-588. https://doi.org/10.1016/j.chb.2017.03.010

Vermunt, J. D. (1996). Metacognitive, cognitive and affective aspects of learning styles and strategies: A phenomenographic analysis. Higher Education, 31(1), 25-50.

Vieru, D., Bourdeau, S., Bernier, A., \& Yapo, S. (2015). Digital competence: A multi-dimensional conceptualization and a typology in an SME context (pp. 4681-4690). Hawaii International Conference on System Sciences.

Westland, J. C. (2010). Lower bounds on sample size in structural equation modeling. Electronic Commerce Research and Applications, 9(6), 476-487. https://doi.org/ 10.1016/j.elerap.2010.07.003

Winkler, R., Söllner, M., \& Leimeister, J. M. (2021). Enhancing problem-solving skills with smart personal assistant technology. Computers \& Education.

Yang, Z. (2020). A study on self-efficacy and its role in mobile-assisted language learning. Theory and Practice in Language Studies, 10(4), 439-444.

Yazon, A. D., Ang-Manaig, K., Buama, C. A. C., \& Tesoro, J. F. B. (2019). Digital literacy, digital competence and research productivity of educators. Universal Journal of Educational Research, 7(8), 1734-1743. https://doi.org/10.13189/ujer.2019.070812

Yu, A. Y., Tian, S. W., Vogel, D., \& Chi-Wai Kwok, R. (2010). Can learning be virtually boosted? An investigation of online social networking impacts. Computers and Education, 55(4), 1494-1503. https://doi.org/10.1016/j.compedu.2010.06.015

Zhao, X., Lynch, J. G., \& Chen, Q. (2010). Reconsidering Baron and kenny: Myths and truths about mediation analysis. Journal of Consumer Research, 37(2), 197-206. https://doi.org/10.1086/651257

Zhou, J. (2017). Exploring the factors affecting learners' continuance intention of moocs for online collaborative learning: An extended ecm perspective. Australasian Journal of Educational Technology, 33(5), 123-135. https://doi.org/10.14742/ajet.2914 